\title{
Preparation of Self-Assembled Monolayer of Dinuclear Iron Complex on Au Electrode and Its Reaction with Molecular Dioxygen
}

\author{
Yuya Hayashi, Tomohiko Inomata, Kazuma Shinozaki, Yasuhiro Funahashi, \\ Tomohiro Ozawa, and Hideki Masuda* \\ Department of Applied Chemistry, Nagoya Institute of Technology, Gokiso-cho, Showa-ku, Nagoya 466-8555 \\ Fax: 81-52-735-5209, e-mail: masudahideki@nitech.ac.jp
}

Diiron(II) complex with a new dinucleating ligand containing terminal amino group, 2,6bis[bis(6-pivalamido-2-pyridylmethyl)aminomethyl]-4-aminophenol (tppap) (1), [ $\mathrm{Fe}_{2}($ tppap $\left.)\left(\mathrm{C}_{6} \mathrm{H}_{5} \mathrm{COO}\right)_{2}\right]^{+}$ (2), was synthesized. The self-assembled monolayer (SAM) of 2, 2/Au, was prepared by the coupling reaction between 2 and activated ester-modified Au electrode. The redox behavior of $2 / \mathrm{Au}$ was observed in aqueous solution at room temperature, which suggests that 2 on Au surface has been stabilized as compared with 2 in homogeneous solution. In addition, the redox potentials of $2 / \mathrm{Au}$ assignable to $\mathrm{Fe}_{2}$ (II,II)/(III,III) and $\mathrm{Fe}_{2}(\mathrm{II}, \mathrm{III} / \mathrm{III}, \mathrm{III})$ shifted to negative direction by bubbling of molecular dioxygen, which returned to the original potential by $\mathrm{Ar}$ bubbling. These behaviors were reversible, suggesting that $2 / \mathrm{Au}$ can reversibly bind/release molecular dioxygen in aqueous solution at room temperature.

Key words: diiron complex, molecular oxygen, peroxo complex, self-assembled monolayer

\section{INTRODUCTION}

The binding and activation of molecular oxygen $\left(\mathrm{O}_{2}\right)$ by non-heme iron proteins are key processes in biological systems. A class of proteins such as hemerythrin $(\mathrm{Hr})$ and methane monooxygenase (MMO), which have similar structural motif of two carboxylate-bridged diiron sites, have received much interest in the past decade [1-5].

$\mathrm{Hr}$ binds $\mathrm{O}_{2}$ as terminal peroxide by $2 \mathrm{e}^{-}$reduction with diiron center, which can bind/release $\mathrm{O}_{2}$ reversibly. On the contrary, $\mathrm{MMO}$ activates $\mathrm{O}_{2}$ to convert methane to methanol under very mild condition at normal pressure and room temperature. Mechanism of $\mathrm{O}_{2}$ activation by MMO is $4 \mathrm{e}^{-}$reduction process accompanied by formation of the diiron(IV) species named compound $Q$, which is converted from peroxo intermediate [5].

Numerous studies on diiron model complexes have much contributed to the understanding of the structural and catalytic properties of their active sites. However, almost diiron model complexes can generate $\mathrm{O}_{2}$ adduct only in non-aqueous solution at low temperature [6-10]. For example, we previously synthesized $\mathrm{Fe}_{2}$ complex using dinucleating ligand [11]. This complex irreversibly reacted with $\mathrm{O}_{2}$ to form $\mu$-peroxo complex in acetone at $-60^{\circ} \mathrm{C}$. When this peroxo complex was heated till room temperature, it was decomposed completely.

The self-assembled monolayers (SAMs) on various metal or metal oxide surfaces have recently received much attention as one of the important tools in nanotechnology and molecular engineering [12-17]. This method allows the introduction of desired functions on the surface at the molecular scale by self-assembling of specific molecular groups such as metal complexes and proteins. In addition, the molecules modified on an electrode surface generally become more stable than that in homogeneous solution. Thus, we attempted the modification of non-heme diiron model complex on the electrode surface by self-assembling method.

Herein, we report the preparation of diiron(II) complex (2) with new dinucleating ligand containing terminal amino group (1) and its self-assembled monolayer, 2/Au (Figs. 1 and 2). 2 on 2/Au was remarkably stable and bound with $\mathrm{O}_{2}$ in aqueous solution at room temperature reversibly. (a)

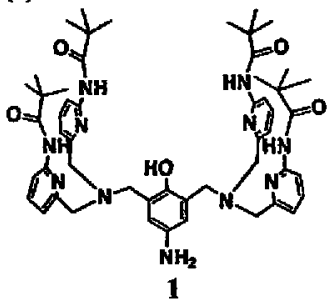

(b)

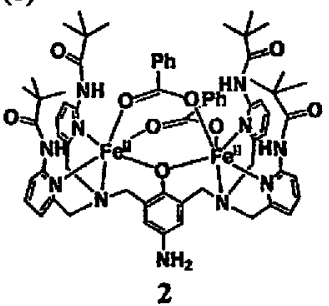

Fig. 1. Schematic views of ligand 1 (a) and complex 2 (b).

\section{EXPERIMENTAL}

$\mathrm{Fe}\left(\mathrm{CF}_{3} \mathrm{SO}_{3}\right)_{2} \cdot 4 \mathrm{CH}_{3} \mathrm{CN}$ was prepared from iron powder and $\mathrm{CF}_{3} \mathrm{SO}_{3} \mathrm{H}$ [18]. All other chemicals were commercially available and used without further purification.

All the manipulations for preparation of the ligand and the diiron(II) complex were carried out under argon atmosphere. Ligand 1 and complex 2 were prepared by modification of the previous method $[11,19]$. The detailed synthetic methods of 1 and 2 are described below: 
Ligand 1.

2,6-Bis[bis(6-pivalamido-2-pyridylmethyl)aminomet hyl]4-nitrophenol $(0.5 \mathrm{mmol})$ was dissolved in a small amount of dry $\mathrm{MeOH}$, and thereto $10 \% \mathrm{Pd}-\mathrm{C}$ (catalytic amount) and anhydrous ammonium formate $(2.4 \mathrm{mmol})$ were added. After the reaction solution (slightly exothermic) was stirred at room temperature for about 4 hours, a white powder was deposited. The powder and catalyst were collected by filtration and washed with methanol. After only the powder was dissolved in chloroform, the residue was removed by filtration through a celite pad. The chloroform solution was evaporated under a reduced pressure to give white powder, which was dried in vacuo. Yield $68.9 \%$. ${ }^{1} \mathrm{HNMR}\left(\mathrm{CDCl}_{3}, 300 \mathrm{MHz}\right) \delta=1.31(36 \mathrm{H}, \mathrm{s}, t-\mathrm{Bu})$, $3.71(4 \mathrm{H}, \mathrm{s}, \mathrm{CH}), 3.75(8 \mathrm{H}, \mathrm{s}, \mathrm{CH}), 6.66(2 \mathrm{H}, \mathrm{s}, \mathrm{Ar})$, $7.16(4 \mathrm{H}, \mathrm{d}, \mathrm{py}, J=7.5 \mathrm{~Hz}), 7.60(4 \mathrm{H}, \mathrm{t}, \mathrm{py}, J=7.8 \mathrm{~Hz})$, $8.07(4 \mathrm{H}, \mathrm{d}$, py, $J=8.1 \mathrm{~Hz}), 8.08(4 \mathrm{H}, \mathrm{br}, \mathrm{NH})$. MS $\mathrm{m} / \mathrm{z} 928.5[\mathrm{M}+\mathrm{H}]^{+}$.

\section{Complex 2.}

A $2 \mathrm{~mL}$ of $\mathrm{MeOH}$ solution of $\mathrm{Fe}\left(\mathrm{CF}_{3} \mathrm{SO}_{3}\right)_{2} \cdot 4 \mathrm{CH}_{3} \mathrm{CN}$ (0.2 mmol) was added to $2 \mathrm{~mL}$ of $\mathrm{CH}_{2} \mathrm{Cl}_{2}$ solution of TPPAP $(0.1 \mathrm{mmol})$. To the resultant solution was added $2 \mathrm{~mL}$ of $\mathrm{MeOH}$ containing $\mathrm{C}_{6} \mathrm{H}_{3} \mathrm{COONa}(0.2$ mmol) and $\mathrm{Et}_{3} \mathrm{~N}(0.1 \mathrm{mmol})$. The resultant yellow solution was allowed to stand for several days to give yellow crystals, which was collected by filtration, washed with methanol and ether, and dried in reduced pressure. Yield $34 \%$. Found: C, 55.97; $\mathrm{H}, 5.21 ; \mathrm{N}$, $10.57 \%$. Calcd. for $2\left(\mathrm{CF}_{3} \mathrm{SO}_{3}\right) \cdot \mathrm{MeOH}: \mathrm{C}, 55.86 ; \mathrm{H}$, $5.65 ; \mathrm{N}, 10.54 \%$.

\section{Preparation of 2/Au.}

The Au electrode was prepared by the evaporation of Au $(99.999 \%)$ on mica with $1,000-\AA$ thickness. The monolayer of 3,3'-dithiobis(succinimidylpropionate) (DTSP) was prepared by immersing of the annealed Au electrode in acetone solution of DTSP ( $4 \mathrm{mM}$ ) for $1 \mathrm{~min}$. After rinsing with acetone and $\mathrm{MeOH}$, the resultant SAM was dipped into $\mathrm{MeOH}$ solution of $2(1 \mathrm{mM})$ for one day (Fig. 2).

\section{Measurements.}

UV-vis absorption spectra were taken on a Jasco V-570 spectrophotometer with a UNISOKU temperature controller. ${ }^{1} \mathrm{H}$ NMR spectra were measured with a
Gemini $300 \mathrm{MHz}$ NMR spectrometer in $\mathrm{CDCl}_{3}$ with TMS as an internal reference standard. Cyclic voltammograms were recorded by ALS600A electrochemical analyzer with a custom-made three-electrode configuration electrochemical cell. Each voltammogram was measured in an aqueous solution containing $0.1 \mathrm{M}$ of $\mathrm{NaCF}_{3} \mathrm{SO}_{3}$ with $\mathrm{Ag} / \mathrm{AgCl}$ reference electrode or $0.1 \mathrm{M}$ of $\mathrm{TBAClO}_{4}$ in $\mathrm{CH}_{3} \mathrm{CN}$ was $0.01 \mathrm{M} \mathrm{Ag} / \mathrm{AgNO}_{3}$ in $0.1 \mathrm{M} \mathrm{TBAClO}{ }_{4}(0.6 \mathrm{~V}$ ws. $\mathrm{Fc} / \mathrm{Fc}^{+}$). The counter electrode was a coiled platinum wire. The working electrode was a glassy carbon for measurement of 2 in solution and a vapor-evaporated $\mathrm{Au}$ for 2/Au. ESI-MS spectra were measured on a Micromass LCT API-TOF MS with a nanoelectrospray source. All spectra were obtained by spraying a $\mathrm{MeOH}$ solution.

\section{RESULTS AND DISCUSSION}

\subsection{Oxygenation reaction of 2 in solution}

Fig. 3 indicates the UV-vis spectral change of reaction of 2 with dioxygen in acetone at $-60^{\circ} \mathrm{C}$, in which the solution color turned from yellow to violet. After the reaction with $\mathrm{O}_{2}$, a broad peak at $\lambda_{\max }=585$ $\mathrm{nm}\left(\varepsilon=3,200 \mathrm{M}^{-1} \mathrm{~cm}^{-1}\right)$ appeared (Fig. 3b), which was assigned to LMCT band of the peroxo to Fe(III) ion based on comparison with the behaviors in similar peroxo diiron complexes [9]. This peak disappeared with increase in temperature (Fig. 3c), suggesting that the peroxo complex is stable only at low temperature.

From the result of X-ray crystallography, it has been clarified that 2 has two Fe centers bridged by two benzoate and one phenoxo groups, and the charge of the complex has been determined to be +2 from the existence of one counter anion $\left(\mathrm{CF}_{3} \mathrm{SO}_{3}\right)$ [11]. The hydrogen bond is formed between $\mathrm{N}-\mathrm{H}$ site of pivalamido group and $\mathrm{O}$ atom of bridging benzoate. This hydrogen bond induces the electron delocalization of the carboxyl group of the bridged benzoate, resulting that the bridging benzoate group is easy to leave. From these findings, we suggested that the oxygenation of 2 proceed via a five-coordinated species: one of two benzoate groups has been kept by the effect of hydrogen bonds. Similar diimon complex without pivalamido groups did not generate peroxo adduct [20]. Thus, 2 would react with $\mathrm{O}_{2}$ to generate $\mu$-peroxo complex.
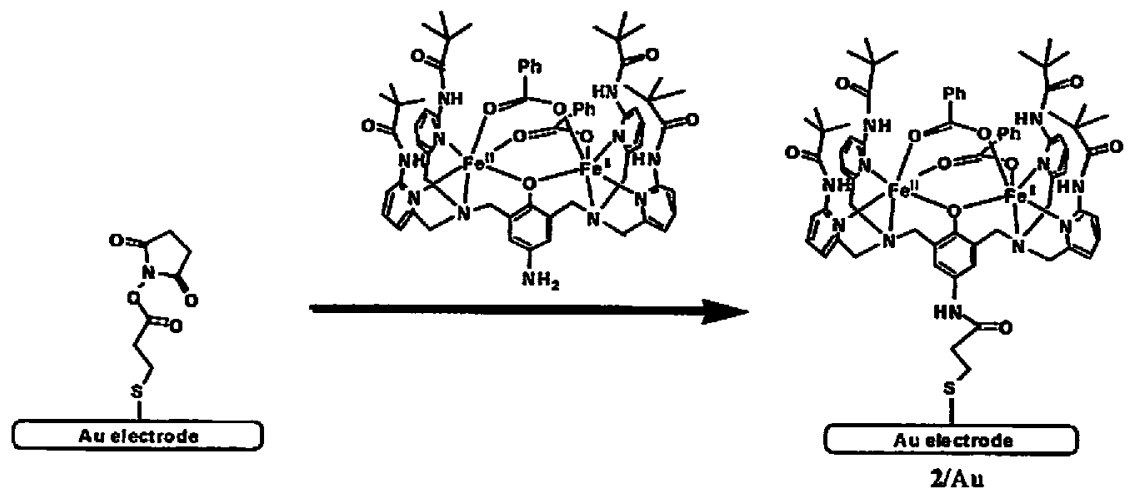

Fig. 2. Pseparation of 2/Au. 


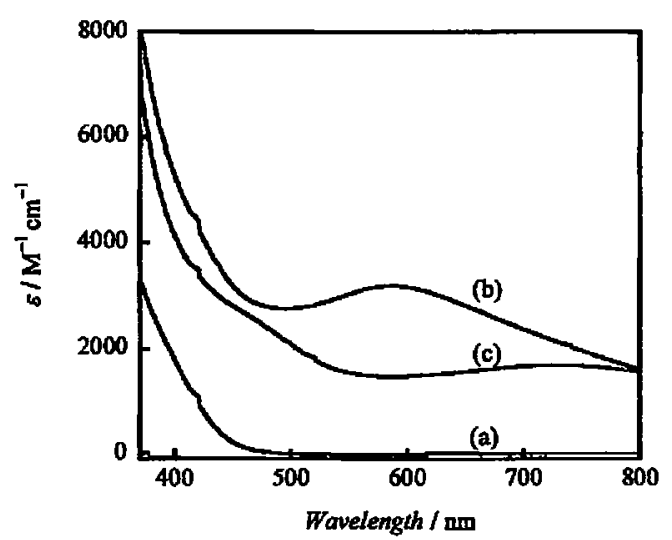

Fig. 3. UV-vis spectral change of 2 in acetone under $\operatorname{Ar}(\mathrm{a}), \mathrm{O}_{2}$ (b) at $-60^{\circ} \mathrm{C}$, and under $\mathrm{O}_{2}$ with rising up to room temperature (c), respectively.

3.2 Redox behavior of 2 in solution and on Au electrode

Fig. 4 shows the cyclic voltammogram of 2 in $\mathrm{CH}_{2} \mathrm{Cl}_{2}$. One anodic wave (2e process) and two cathodic waves (two $1 \mathrm{e}^{-}$processes) were observed at $E_{\mathrm{pa}}$ $=0.92 \mathrm{~V}$ and $E_{\mathrm{pc}}=0.67,0.40 \mathrm{~V}$ vs. $\mathrm{Ag} / \mathrm{Ag}^{+}$, assignable to $\mathrm{Fe}_{2}(\mathrm{II}, \mathrm{II} / \mathrm{II}, \mathrm{III}), \mathrm{Fe}_{2}$ (II,II/II,III), and $\mathrm{Fe}_{2}$ (II,III/II,III) couples, respectively, which corresponded well to those of the $\mathrm{Fe}_{2}$ complexes with similar structures previously reported. Each redox process was not reversible, suggesting that 2 in $\mathrm{CH}_{2} \mathrm{Cl}_{2}$ is not so stable. This instability is probably explained in terms of the hydrogen bond between $\mathrm{N}-\mathrm{H}_{\text {pivalemido }}$ and $\mathrm{O}_{\text {benzoate. }}$ The bridging benzoate can easily release from one $O$ site that is not restricted by hydrogen bond, so 2 may form several structures in solution.

The cyclic voltammogram of $2 / \mathrm{Au}$ in aqueous solution showed one anodic wave ( $2 \mathrm{e}^{-}$process) and two cathodic waves (two $1 \mathrm{e}^{-}$processes) at $E_{\mathrm{pa}}=-0.32 \mathrm{~V}$ and $E_{\mathrm{pc}}=-0.38,-0.55 \mathrm{~V}$ vs. $\mathrm{Ag} / \mathrm{AgCl}$ (Fig. $5 \mathrm{a}$ ). The linear relationship between peak currents and scan rates indicates that this redox process is originated from the species immobilized on the surface. Thus, it has been demonstrated that $\mathbf{2}$ is modified on the Au surface. Compared to the above result in solution, these waves were assigned to $\mathrm{Fe}_{2}(\mathrm{II}, \mathrm{II}) /(\mathrm{III}, \mathrm{III}), \mathrm{Fe}_{2}$ (II,II)/(II,III), and

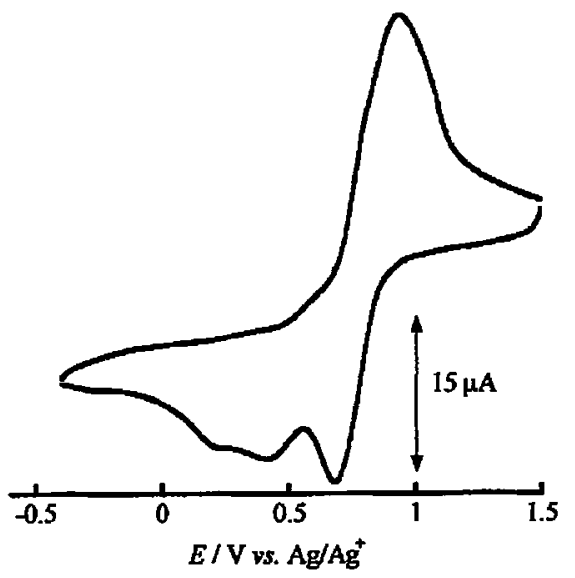

Fig. 4. Cyclic voltammogram of 2 in $\mathrm{CH}_{2} \mathrm{Cl}_{2}$. containing $0.1 \mathrm{M} \mathrm{TBAClO}_{4}$. Scan rate is $0.1 \mathrm{~V} \mathrm{~s}^{-1}$.
$\mathrm{Fe}_{2}$ (Il,III)/(III,III) couples, respectively. Each redox potential of 2/Au widely shifted to the negative direction compared to 2 in solution. This shift has probably been caused by the effect of negatively charged surface by linking of DTSP. Similar negative shift of the redox potential of complexes immobilized on the surface have been reported [17].

\subsection{Oxygenation reaction of $2 / \mathrm{Au}$}

The redox potential of $2 / \mathrm{Au}$ in aqueous solution dramatically changed by bubbling of $\mathrm{O}_{2}$ gas. The waves assigned to $\mathrm{Fe}_{2}$ (II,II/III,III), and $\mathrm{Fe}_{2}$ (II,IIIII,III) shifted to negative direction ( $c a .0 .08 \mathrm{~V}$ ) in comparison with those before the bubbling (Fig. 5b). In addition, these two redox potentials shifted to positive direction by $\mathrm{Ar}$ bubbling and finally returned to the original potentials. This change was repeated reversibly. Thus, the waves of Fig. $5 \mathrm{~b}$ were assigned to the waves of $\mu-1,2$-peroxo complex, $\mathrm{Fe}_{2}\left(\mathrm{O}_{2}\right)(\mathrm{II}, \mathrm{IIII}, \mathrm{III})$ and $\mathrm{Fe}_{2}\left(\mathrm{O}_{2}\right)(\mathrm{II}, \mathrm{III} / \mathrm{II}, \mathrm{III})$, respectively. This finding indicates that the reversible $\mathrm{O}_{2}$ adsorption/desorption has occurred on $2 / \mathrm{Au}$ in aqueous solution at room temperature. That is, the peroxo complex of 2 became extremely stable by modifying on Au surface. Here we can state that complex 2 on 2/Au has behaved like the solid state to prevent the degradation of 2 ; the peroxo adduct of 2 has been stabilized in aqueous solution at

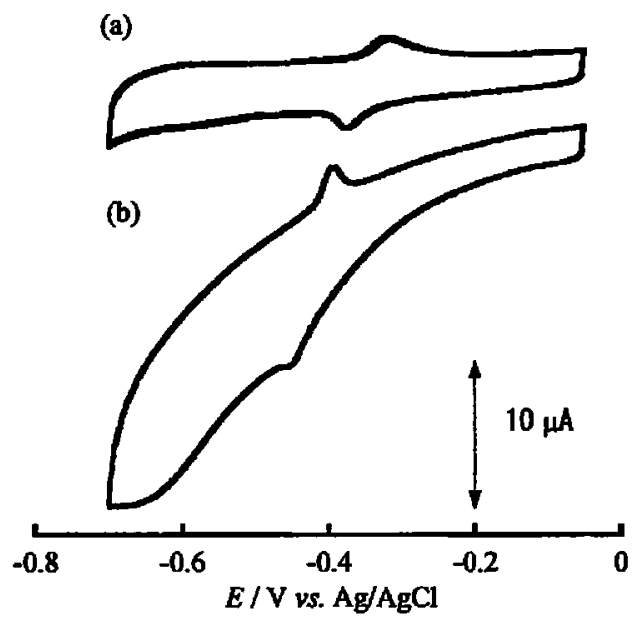

Fig. 5. Cyclic voltammograms of $2 / \mathrm{Au}$ in $0.1 \mathrm{M}$ $\mathrm{NaCF}_{3} \mathrm{SO}_{3}$ aqueous solution (a) under $\mathrm{Ar}$ and (b) after bubbling of $\mathrm{O}_{2}$. Scan rate is $0.05 \mathrm{~V} \mathrm{~s}^{-1}$.

room temperature.

\section{CONCLUSION}

In summary, we prepared self-assembled monolayer of diiron(II) complex, 2/Au, and observed the interesting redox behavior by captured molecular oxygen in aqueous solution at room temperature. We also succeeded in observation of its reversible oxygen adsorption/ desorption. The immobilization of 2 onto Au electrode surface makes it stabilize extremely. This is the rare example that the reversible adsorption/desorption of dioxygen has been observed by the immobilization of the non-heme functional model complex on the electrode. 


\section{Acknowledgments}

This work was supported by a Grant-in-Aid for Scientific Research from the Ministry of Education, Culture, Sports, Science and Technology of Japan and supported in part by a grant from the NITECH 21st Century COE Program, to which our thanks are due.

\section{References}

[1] P. C. Wilkins, R. G. Wilkins, Coord. Chem. Rev., 79, 195-2 14 (1987).

[2] R. E. Stenkamp, Chem. Rev., 94, 715-26 (1994).

[3] M. -H. Baik, M. Newcomb, R. A Friesner, S. J. Lippard, Chem. Rev., 103, 2385-420 (2003).

[4] B. J. Wallar, J. D. Lipscomb, Chem. Rev., 96, 2625-58 (1996).

[5] L. J. Shu, J. C. Nesheim, K. Kauffimann, E. Munck, J. D. Lipscomb, L. Que, Jr., Science, 275, 515 (1997).

[6] N. Kitajima, N. Tamura, H. Amagai, H. Fukui, Y. Moro-oka, Y. Mizutani, T. Kitagawa, R. Mathur, K. Heerwegh, C. A. Reed, C. R. Randall, L. Que, Jr., K. Tasumi, J. Am. Chem. Soc., 116, 9071-85 (1994).

[7] Y. Hayashi, T. Kayatani, H. Sugimoto, M. Suzuki, K. Inomata, A. Uehara, Y. Mizutani, T. Kitagawa, Y. Maeda, J. Am. Chem. Soc., 117, $11220-9$ (1995).

[8] T. Ookubo, H. Sugimoto, T. Nagayama, H. Masuda, T. Sato, K. Tanaka, Y. Maeda, H. Okawa, Y. Hayashi, A. Uehara, M. Suzuki, J. Am. Chem. Soc., 118, 701-2 (1996).

[9] M. Suzuki, H. Furutachi, H. Okawa, Coord. Chem. Rev., 200-202, 105-29 (2000).

[10] H. Zheng, S. J. Yoo, E. Munck, L. Que, Jr., J. Am. Chem. Soc., 122, 3789-90 (2000).

[11] Unpublished results.

[12] H. Yamada, H. Imahori, Y. Nishimura, I. Yamazaki, S. Fukuzumi, Chem. Commun, 1921-22 (2000).

[13] T. Inomata, M. Abe, T. Kondo, K. Umakoshi, K. Uosaki, Y. Sasaki, Chem. Lett., 1097-98 (1999).

[14] Jerzy Zak, Hongping Yuan, Mankit Ho, L. Keith Woo, Marc D. Porter, Langmuir, 9, 2772-4 (1993).

[15] K. Fujita, N. Nakamura, N. Ohno, B. S. Leigh, K. Niki, H. B. Gray, J. H. Richards, J. Am. Chem. Soc., 126, 13954-61 (2004).

[16] K. Nakano, K. Doi, K. Tamura, Y. Katsumi, M. Tazaki, Chem. Commun, 1544-5 (2003).

[17] H. Wackerbarth, F. B. Larsen, A. G. Hansen, C. J. Mckenzie, J. Ulstrup, Dalton Trans., 3438-44 (2006).

[18] K. S. Hangen, Inorg. Chem., 39, 5867-9 (2000).

[19] M. Suzuki, H. Kanatomi, I. Murase, Chem. Lett., 1745-8 (1981).

[20] M. Suzuki, A. Uehara, H. Oshio, K Endo, M. Yanaga, S. Kida, K. Saito, Bull. Chem. Soc. Jpn, 60, 3547-55 (1987). 